\title{
QUANTITATIVE AND QUALITATIVE ANALYSIS OF FIXED-DOSE-COMBINATION PRODUCTS (FDC, POLYPILL) APPLIED IN POLYTHERAPY OF HYPERTENSIVE DISEASE. REVIEW
}

\author{
MARIUSZ STOLARCZYK*, ANNA APOLA, ANNA MAŚLANKA, ANNA KWIECIEŃ \\ and WŁODZIMIERZ OPOKA
}

Department of Inorganic and Analytical Chemistry, Jagiellonian University Medical College,
Faculty of Pharmacy, 9 Medyczna Street, 30-688 Kraków, Poland

\begin{abstract}
Problems in polytherapy of hypertension combined with hyperlipidemia and the need of application of several pharmaceutical preparations have been widely explored by patients, physicians, and the pharmaceutical industry through testing and introduction of a fixed-dose-combination products (FDC). The paper presents different analytical methods of qualitative and quantitative analysis or stability testing of FDC preparations and laboratory prepared mixtures of composition consistent with the FDC products collected on the basis of publications from the last decade. It can significantly facilitate the study of the methods and conditions for the determination of active substances in polypills which contain at least three APIs, especially in cases involving this type of preparations used or tested for their application in polytherapy of hypertension.
\end{abstract}

Keywords: Fixed-dose combination drugs, analysis

\begin{abstract}
Abbreviations: FDC - fixed-dose-combination, ACEI - angiotensin-converting-enzyme inhibitors, ARB angiotensin receptor blockers, TIPS - The Indian POLYCAP Study, IMPACT - IMProving Adherence using Combination Therapy, HOPE - Heart Outcomes Prevention Evaluation, HPLC - high-pressure liquid chromatography, LC - liquid chromatography, LC-MS - liquid chromatography-mass spectrometry, MEKC micellar electrokinetic chromatography, LOD - limit of detection, LOQ - limit of quantitation
\end{abstract}

Cardiovascular diseases in addition to cancer and infectious diseases are the leading causes of death in the world. According to WHO data, it is estimated that in 2012, 17.5 million people died of cardiovascular disease worldwide or of complications, which is $31 \%$ of all deaths. It was assessed that 7.4 million of these deaths were due to ischemic heart disease and 6.7 million were caused by stroke. The highest number of deaths, about 13.2 million, was reported in low or middle-income countries. It has been estimated that of the 16 million deaths caused by non-infectious diseases, among the population below 70 years $82 \%$ refer to low- and middleincome countries, $37 \%$ were caused by cardiovascular diseases $(1,2)$.

The possibility of cardiovascular disease can be reduced by eliminating certain factors that increase the likelihood of its occurrence. Tobacco smoking, abnormal lipid levels, abnormal diet, physical inactivity, obesity, and diabetes are the main risk factors (3). People with cardiovascular disease or who are at high risk of cardiovascular disease (due to the presence of one or more risk factors such as hypertension, diabetes, hyperlipidemia) must be subjected to early diagnosis and therapy. Then the correct system of treatment should be selected with the use of various individually indicated pharmaceutical preparations. The most commonly used in polytherapy pharmacological classes are antithrombotic agents, $\beta$-blockers, angiotensin converting enzyme inhibitors (ACEI), angiotensin receptor blockers (ARBs), statins, diuretics, and calcium channel blockers.

Such a large number of different substances requires the optimization of the treatment in terms of its effectiveness and potential side effects. In the majority of cases, patients treated for cardiovascular disease are forced to take 2, 3 and sometimes 4 different pharmaceutical preparations whose synergistic effects improve cardiovascular system. In addition, you may need to take other medicines that are not directly related to cardiovascular treatment, such

* Corresponding author: e-mail: mariusz.stolarczyk@uj.edu.pl 
as anti-inflammatory drugs, analgesic drugs, or antihistamines.

In 2003, Wald and Law introduced the concept of a polypill (4). It referred to the pharmaceutical preparation composed of a statin, for example atorvastatin (daily dose $10 \mathrm{mg}$ ) or simvastatin (40 mg), three blood pressure lowering drugs (for example thiazide, a $\beta$ blocker, and an angiotensin converting enzyme inhibitor) each at half standard dose, folic acid $(0.8 \mathrm{mg})$ and acetylsalicylic acid $(75 \mathrm{mg})$. Since then there has been a clear development of the concept of polypills, but the basic character of its composition remained unchanged. In many countries, a number of randomized studies have been carried out to determine the effect of the use of this type of drug in a particular group of patients compared to placebo or to polytherapy with one or two-component preparations.

\section{Effects of clinical studies}

Studies of TIPS and TIPS 2 were conducted on a group of 2053 patients at the age of 45-80 and showed that administration of a polypill composed of hydrochlorothiazide, atenolol, ramipril, simvastatin, and acetylsalicylic acid brings measurable effects in the form of lowering cholesterol and blood pressure $(4,6)$. A more effective decrease in cholesterol levels has been reported in patients with diabetes. The occurrence of side effects statistically did not differ from the value seen in the treatment group taking one-component drugs, which, according to the authors, contradicts the theory that the increase in the amount of components in a polypill increases the likelihood of side effects. The authors assessed that the use of a polypill may reduce the risk of cardiovascular events by up to $60 \%$, which is the basis for further research.

In 2008-2009, the Pill Collaborative Group conducted the study of 378 participants aged 50-70 years. The effects of a polypill composed of acetylsalicylic acid, lisinopril, hydrochlorothiazide and simvastatin on the reduction of systolic blood pressure and lipid level were evaluated. After 12 weeks the obtained results were statistically evaluated and a decrease in cholesterol level and systolic blood pressure was observed. At the same time, side effects were observed in about $17 \%$ of the patients (7).

In the case of studies conducted by Malekzadeh and Wald in groups of patients aged over 50 years, a decrease of systolic blood pressure and lipid levels was also observed $(8,9)$. The analysis of the results obtained after the application of a polypill composed of acetylsalicylic acid, enalapril, atorvas- tatin, and hydrochlorothiazide showed a statistically significant decrease of these parameters that was not as clear as in the case of a Wald's polypill (amlodipine, losartan, hydrochlorothiazide, and simvastatin). This may be due to the replacement of one antihypertensive drug (enalapril) by two drugs (amlodipine and losartan).

Slightly different results of studies on the application of polypills are presented in publications where the polypills of similar composition were used (10-12). In both cases, the authors underline the high acceptability of polypills among physicians and patients and a smaller percentage of patients who discontinued treatment because of the need to take several preparations at the same time. The economic aspect in which the lower cost of complex preparations has a significant impact on improving the availability of specific therapy, especially in low-income patients, has also been highlighted. Referring to results such as blood pressure or lipid levels, the authors did not observe statistically significant differences compared to the control group taking certain drugs in the form of one-component pharmaceutical preparations.

The IMPACT study (13) is a randomized study evaluating the efficacy of a polypill (acetylsalicylic acid, simvastatin, lisinopril, and either hydrochlorothiazide or atenolol) in patients at the high risk of cardiovascular diseases. The results presented by the authors showed a great potential of polypills both in pharmacological and economic aspect (13). The lack of observed side effects and the greater effectiveness of adherence to the recommendations and control by patients and physicians may have a significant impact on the health status of patients at risk of complications related to the cardiovascular disease.

The HOPE-3 study is aimed at assessing whether rosuvastatin, candesartan and hydrochlorothiazide applied in the form of a polypill, or as a single pharmaceutical formulation, will have a statistically significant effect on the reduction of cholesterol and blood pressure, and can reduce the risk of heart attack, stroke and their consequences compared to placebo (14).

SECURE is a clinical trial, which is scheduled for 2020, testing the efficacy of a polypill in a secondary prevention of cardiovascular diseases, in the elderly population. It is run in 7 European countries: Czech Republic, France, Germany, Hungary, Italy, Poland, and Spain. During studies, it will be assessed whether the use of a polypill, containing three active substances of proven efficacy (acetylsalicylic acid, atorvastatin and ramipril) will reduce 


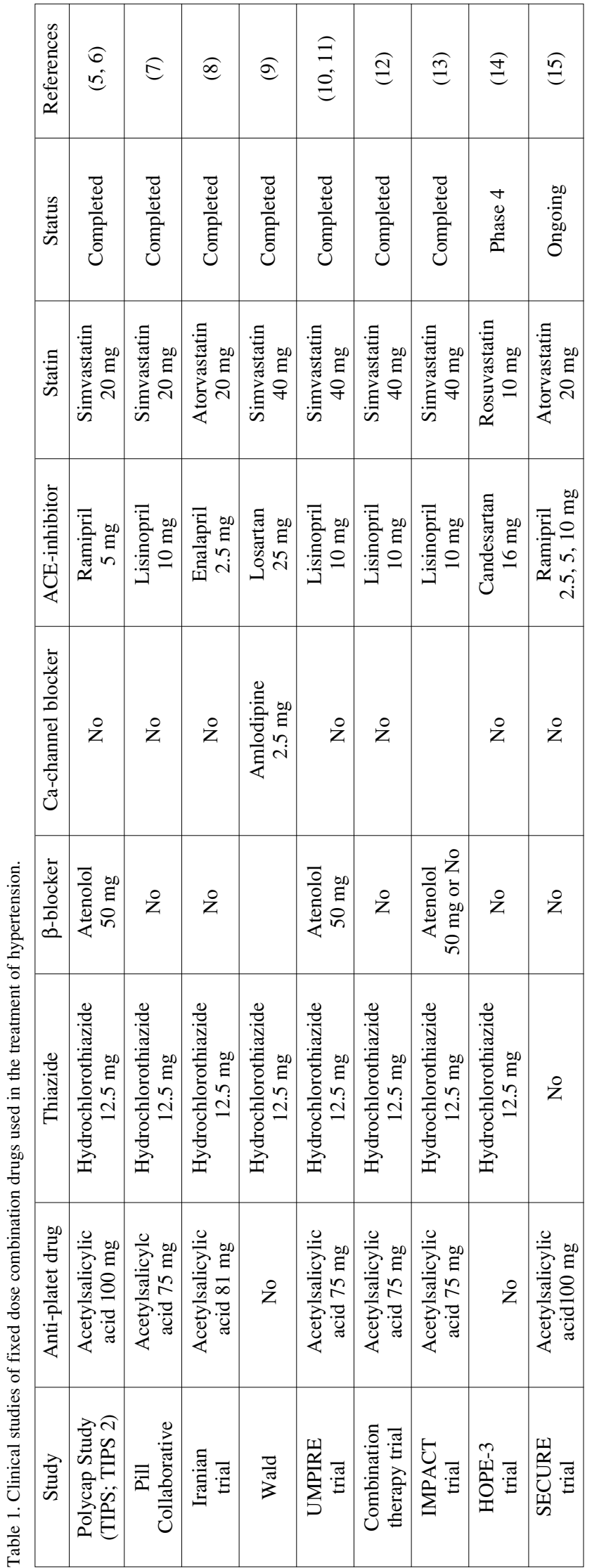

the occurrence of major cardiovascular incidents in patients after acute myocardial infarction (15). Some of the obtained results have already been published and some studies are still carried out. The results are presented in Table 1.

\section{Analytical methodology}

The relatively new topic of the analysis of pharmaceutical preparations used in the form of polypills requires the application of separation techniques in the majority of cases.

Pawar proposed the RP-HPLC method for the analysis of a mixture composed of enalapril maleate, hydrochlorothiazide, acetylsalicylic acid and atorvastatin (16). The separation was achieved using Lichrosphere 100 RP-18 reversed phase $\mathrm{C} 18$ column $(250 \times$ $4.6 \mathrm{~mm}$, particle size $5 \mu \mathrm{m}$ ). As a mobile phase, the author used a mixture of methanol: acetonitrile: triethylammonium phosphate buffer at a flow rate of $0.6 \mathrm{~mL} / \mathrm{min}$. Spectrophotometric detection was performed at a wavelength of $225 \mathrm{~nm}$. Under these conditions, welldeveloped and separated peaks of individual components with the retention times ranging from $3.67 \mathrm{~min}$. to $8.3 \mathrm{~min}$. were obtained. The method was characterized by a wide linearity range, high accuracy, and precision. The experimentally determined LOD was $1.474 \mu \mathrm{g} / \mathrm{mL}$ for acetylsalicylic acid, $0.737 \mu \mathrm{g} / \mathrm{mL}$ for hydrochlorothiazide, $0.545 \mu \mathrm{g} / \mathrm{mL}$ for enalapril and $1.641 \mu \mathrm{g} / \mathrm{mL}$ for atorvastatin. The LOQ was $4.466 \mu \mathrm{g} / \mathrm{mL}$, $2.233 \mu \mathrm{g} / \mathrm{mL}, 1.653 \mu \mathrm{g} / \mathrm{mL}$ and 4.972 $\mu \mathrm{g} / \mathrm{mL}$, respectively. The composition of the model mixture was not determined in this case by a specific quantitative ratio based on, for example, commonly available pharmaceutical formulations containing individual ingredients or commonly accepted dosage regimens, but was determined by the validation parameters.

Identical mobile-phase in terms of qualitative composition, changed in terms of the ratios of the individual components, ie. acetonitrile, methanol and triethylammonium phosphate buffer were used for the analysis of a mixture 
composed of acetylsalicylic acid, ramipril, metoprolol and atorvastatin using the RP-HPLC method. The quantitative composition of this mixture was determined by the quantitative ratio of the constituents in the Zycad-4 pharmaceutical formulation (17). Using Lichrosphere $100 \mathrm{RP}-18$ reversed phase C18 column $(250 \times 4.6 \mathrm{~mm}$, particle size $5 \mu \mathrm{m})$, mobile phase flow rate $0.8 \mathrm{~mL} / \mathrm{min}$ and spectrophotometric detection at $225 \mathrm{~nm}$, the authors obtained a satisfactory separation of determined components with retention times of: $4.117 \mathrm{~min}$ for acetylsalicylic acid, $5.90 \mathrm{~min}$ for atorvastatin, $7.158 \mathrm{~min}$ for ramipril and $8.333 \mathrm{~min}$ for metoprolol. The total analysis time under the described conditions was 15 min. The tested linearity range was wide and the LOD value for the individual components was 3.052 $\mu \mathrm{g} / \mathrm{mL}$ for acetylsalicylic acid, $3.700 \mu \mathrm{g} / \mathrm{mL}$ for metoprolol, $1.007 \mu \mathrm{g} / \mathrm{mL}$ for ramipril and $0.961 \mu \mathrm{g} / \mathrm{mL}$ for atorvastatin. LOQ was 9.248 $\mu \mathrm{g} / \mathrm{mL}, 11.213 \mu \mathrm{g} / \mathrm{mL}, 3.053 \mu \mathrm{g} / \mathrm{mL}$ and 2.912 $\mu \mathrm{g} / \mathrm{mL}$, respectively. Validation parameters met the ICH requirements for the chromatographic method. Recovery for the Zycad-4 pharmaceutical preparation ranged from $97.8 \%$ to $99.76 \%$ depending on the determined component.

Shetty et al. have proposed an HPLC method with spectrophotometric detection at $230 \mathrm{~nm}$ for the separation of active substances in the pharmaceutical preparation called Star pill (Cipla Ltd.), composed of atorvastatin $10 \mathrm{mg}, 50 \mathrm{mg}$ of atenolol, 50 $\mathrm{mg}$ of losartan and $75 \mathrm{mg}$ of acetylsalicylic acid (18). The stationary phase was Inertsil ODS C18 column $(150 \times 4.6 \mathrm{~mm}$, particle size $5 \mu \mathrm{m})$, while the mobile phase was a mixture of buffer and acetonitrile at a flow rate of $1.0 \mathrm{~mL} / \mathrm{min}$. Under these conditions, well separated and developed peaks of examined substances with the retention times 12.9 min for atorvastatin, $3.3 \mathrm{~min}$ for atenolol, $10.7 \mathrm{~min}$ for losartan, and $7.6 \mathrm{~min}$ for acetylsalicylic acid, were determined at the total analysis time of $20 \mathrm{~min}$. The studied linearity range was wide and ranged from 5.0 to $20.0 \mu \mathrm{g} / \mathrm{mL}$ for atorvastatin, 37.5 to $150.0 \mu \mathrm{g} / \mathrm{mL}$ for acetylsalicylic acid and 25.0 to $100.0 \mu \mathrm{g} / \mathrm{mL}$ for atenolol and losartan. This choice of linearity ranges allowed the Star pill ingredients to be determined with satisfactory statistical values. Moreover, the authors evaluated the stability of tested substances under different conditions. The behavior of the substances in acidic medium ( 0.1 $\mathrm{mol} / \mathrm{L} \mathrm{HCl}$ for $1 \mathrm{~h})$, alkaline medium $(0.1 \mathrm{~mol} / \mathrm{L}$ $\mathrm{NaOH}$ for $2 \mathrm{~h}$ ), in the presence of oxidants $(5 \%$ $\mathrm{H}_{2} \mathrm{O}_{2}$, room temperature, $48 \mathrm{~h}$ ), during the exposition to light for an overall illumination of 1.2 million lux hours and an integrated near ultraviolet energy of 200 watt-hours/square meter and at $60^{\circ} \mathrm{C}$ for $8 \mathrm{~h}$ was analyzed. Under the studied conditions, it was found that the most sensitive substances in the case of hydrolysis in acidic environment were acetylsalicylic acid, atenolol and atorvastatin, while in alkaline environment atenolol and atorvastatin. The most sensitive substances to oxidants were losartan, atorvastatin and acetylsalicylic acid. Atorvastatin and losartan were the most susceptible to photolysis and atenolol and acetylsalicylic acid to thermolysis. Based on the publication, it can be stated that atorvastatin is the most susceptible to degradation because its degradation rate in all tested cases was high, except for the thermal degradation.

In the paper published in the Journal of Pharmaceutical Analysis, the authors presented a method for the quantitative analysis of 10 substances used in different configurations mainly in the treatment of cardiovascular diseases (19). Due to differences in the partition coefficients of the individual substances, different variants of the mobile phase composition and two types of stationary phase were tested. The optimum separation was achieved by using a mobile phase composed of acetonitrile modified with $0.1 \%$ triethylamine acetate (TEAA) buffer $(\mathrm{pH}=5)$ at a flow rate of $1 \mathrm{~mL} / \mathrm{min}$ and $\mathrm{UV}$ detection at $\lambda=230$ $\mathrm{nm}$. The stationary phase, in this case, was the chromatographic column $5 \mu \mathrm{m}$ phenyl $(250 \mathrm{~mm} \times 4.6 \mathrm{~mm}$ i.d.). When $\mathrm{C} 18$ column was used as a stationary phase, and depending on the modification of the mobile phase, atenolol and acetylsalicylic acid or atorvastatin and telmisartan were not resolved. Under the developed optimum separation conditions, the well-developed peaks were obtained and the following retention times were obtained: metoprolol 4.1 $\mathrm{min}$, atenolol $8.1 \mathrm{~min}$, acetylsalicylic acid $8.5 \mathrm{~min}$, losartan $10.6 \mathrm{~min}$, telmisartan $12.8 \mathrm{~min}$, atorvastatin $13.6 \mathrm{~min}$, glimepiride $15.9 \mathrm{~min}$, ezetimibe $17.2 \mathrm{~min}$, clopidogrel $23.8 \mathrm{~min}$. and for fenofibrate $24.4 \mathrm{~min}$. The tested linearity range for all substances was 50$150 \mathrm{mg} / \mathrm{mL}$ with correlation coefficients greater than 0.9990 in all cases. LOD and LOQ were determined experimentally and were in the range: LOD from 0.13 to $0.27 \mu \mathrm{g} / \mathrm{mL}$ and LOQ from 0.30 to $0.89 \mu \mathrm{g} / \mathrm{mL}$, depending on the tested substance. The developed procedure was used by the authors for the determination of active substances occurring in complex drug formulations. The results did not differ from the declared by the manufacturer content and the values of parameters such as recovery and RSD were in all cases within the criteria of acceptance, recovery of $100 \% \pm 5 \%$ and RSD value not exceeding $1.5 \%$.

Another type of a polypill, composed of simvastatin $20 \mathrm{mg}$, ramipril $5 \mathrm{mg}$, hydrochlorothiazide 
12.5 , atenolol $50 \mathrm{mg}$ and acetylsalicylic acid $100 \mathrm{mg}$ was quantitatively analyzed by Yadav and Rao (20). For this purpose, an RP-HPLC method with a Hypersil ODS C18 column $(250 \times 4.6 \mathrm{~mm}$, particle size $5 \mu \mathrm{m}$ ) was used and a mobile phase composed of methanol: water in the ratio of $95: 5 \% \mathrm{v} / \mathrm{v}$ at a flow rate $1 \mathrm{~mL} / \mathrm{min}$. In this case, as in many previous ones, spectrophotometric detection was used at $230 \mathrm{~nm}$. Such separation conditions allowed the authors to obtain a relatively short analysis time (12 min) where the retention times of the individual components were $1.983,2.525,3.108,3.867$ and $7.833 \mathrm{~min}$ respectively for acetylsalicylic acid, ramipril, hydrochlorothiazide, simvastatin, and atenolol. The linearity ranges of the individual components were $20-120 \mu \mathrm{g} / \mathrm{mL}$ for acetylsalicylic acid, 1-6 $\mu \mathrm{g} / \mathrm{mL}$ for ramipril, $2.5-15 \mu \mathrm{g} / \mathrm{mL}$ for hydrochlorothiazide, $4-24 \mu \mathrm{g} / \mathrm{mL}$ for simvastatin, 10-60 $\mu \mathrm{g} / \mathrm{mL}$ for atenolol and were adjusted to the ratio of the individual components in the polypill. The correlation coefficients of all calibration curves were 0.9996, except for the calibration curve for ramipril whose value was 0.9990 . Detection and quantification limits were calculated using appropriate mathematical formula and were in the following ranges: LOD from 0.2 to $6.6 \mu \mathrm{g} / \mathrm{mL}$, LOQ from 0.5 to 14.0 $\mu \mathrm{g} / \mathrm{mL}$. The authors checked the correctness of the method by analyzing pharmaceutical preparation called Polycap and obtained satisfactory results, confirmed by the statistical analysis. The advantage of the presented procedure may be a simple composition of the mobile phase and a short analysis time.

Polytorva capsules were subjected to qualitative and quantitative analysis by RP-LC and RPHPLC methods (21-22). These polypills are composed of three active substances, namely ramipril $5 \mathrm{mg} /$ tablet, acetylsalicylic acid $75 \mathrm{mg} /$ tablet and atorvastatin $10 \mathrm{mg} /$ tablet. The separation was carried out using a C18 column $(250 \mathrm{~mm} \times 4.6 \mathrm{~mm}$, $5 \mu \mathrm{m}$ particle size). The composition of the mobile phase was very similar, in the LC method a mixture of $0.1 \%$ orthophosphoric acid buffer: acetonitrile: methanol at $\mathrm{pH}=3.3$ was used and in the case of RP-HPLC method, a mixture of acetonitrile: methanol (65:35, v/v) (mixture A) and $10 \mathrm{mM}$ sodium dihydrogen phosphate monohydrate buffer, which was adjusted to $\mathrm{pH}=3.0$ with $10 \%$ orthophosphoric acid (mixture B) was used. The two mixtures were mixed together in a ratio of $60: 40 \mathrm{v} / \mathrm{v}$ to obtain a separation that guarantees correct interpretation of the obtained peaks. The total analysis time of the two methods did not exceed $13 \mathrm{~min}$, and the detection was carried out with a spectrophotometric detector at $\lambda=210 \mathrm{~nm}$ (LC) and at $230 \mathrm{~nm}$ (RP-
HPLC). Under the developed conditions, a clear separation of the active substances was achieved, where the peak area of ramipril was relatively small compared to the other components. This is probably due to the mutual quantitative ratio of ingredients in the studied drug formulations. The retention times of examined substances were 3.62, 4.92 and 11.71 min. for LC method and 2.34, 3.95 and 12.19 min. for RP-HPLC method, for ramipril, acetylsalicylic acid and atorvastatin respectively, and in both cases were comparable. LOD and LOQ, compared to other analyzes of samples of similar composition, were significantly lower. Large differences in their values depending on the method used (with almost the same determination conditions and retention times) can be surprising. In the case of RP-LC, the authors reported LOD values of $4.71,85.13$ and $29.85 \mathrm{ng} / \mathrm{mL}$, while LOQs were respectively 14.28 , 257.97 and $90.45 \mathrm{ng} / \mathrm{mL}$ for ramipril, acetylsalicylic acid and atorvastatin. For RP-HPLC, these values were LOD: $0.014,0.100,0.0095 \mathrm{ng} / \mathrm{mL}$ and LOQ: $0.043,0.329$ and $0.029 \mathrm{ng} / \mathrm{mL}$ for the respective substances. Other validation parameters of the developed method such as accuracy and precision were within acceptable limits. The content of individual components was not significantly different from the content declared by the manufacturer of the pharmaceutical preparation.

Identical in terms of quantitative and qualitative composition pharmaceutical preparation was analyzed by thin-layer chromatography (23). The chromatographic separation was conducted on HPTLC plates with fluorescent indicator (silica gel $\left.60, \mathrm{~F}_{254}\right)$. Chromatograms were developed in a chromatographic chamber, previously saturated with a mobile phase, to a distance of $8 \mathrm{~cm}$. The mobile phase was a mixture of benzene: ethyl acetate: toluene: methanol: glacial acetic acid. After the plates were dried, densitometric detection was performed at $220 \mathrm{~nm}$. The obtained densitogram was characterized by well separated and well-developed peaks of relatively large areas. $R_{F}$ values were 0.28 \pm 0.01 for ramipril, $0.45 \pm 0.02$ for atorvastatin, and $0.72 \pm 0.02$ for acetylsalicylic acid. The linearity range of the method was examined in two concentration ranges: $0.5-2.5 \mu \mathrm{g} / \mathrm{spot}$ for ramipril and atorvastatin and $0.75-3.75 \mu \mathrm{g} / \mathrm{spot}$ for acetylsalicylic acid. Validation parameters such as accuracy, precision or repeatability were comparable to that obtained by the RP-HPLC method. The determined content of active substances in the pharmaceutical preparation was satisfactory (RSD $=$ 99.17$100.75 \%$ ). The obtained results revealed, that the method proposed by the authors may be competitive 
in relation to the RP-HPLC method in terms of costs but definitely differs in terms of analysis time.

Some authors attempt to determine active substances that may hypothetically appear in the form of one tablet because the composition of polypills used in the treatment of cardiovascular disease may be different. In this case, two ways of proceeding are possible. Either the mixture is prepared from standard substances, taking into account the daily dosage of the individual ingredients, or ready-made, commercially available tablets (in the form of one or two-component formulations) are used after trituration. This second option was used for the simultaneous determination of losartan, hydrochlorothiazide and atorvastatin (24). For the preparation of the test samples, the authors used Kanzar-H tablets composed of losartan $100 \mathrm{mg} /$ tablet and hydrochlorothiazide $25 \mathrm{mg} /$ tablet, which were powdered with $20 \mathrm{mg}$ of atorvastatin standard substance. The chromatographic separation was conducted on a Hypersil C18 $(250 \times 4.6 \mathrm{~mm}, 5 \mu \mathrm{m}$ particle size $)$ column at $40^{\circ} \mathrm{C}$; the mobile phase was composed of acetonitrile : $0.2 \mathrm{M}$ phosphate buffer $(50: 50, \mathrm{v} / \mathrm{v})$ at a flow rate of $1.5 \mathrm{~mL} / \mathrm{min}$. As in most cases, an analytical wavelength of $230 \mathrm{~nm}$ was chosen when the spectrophotometric detector was used. The determined linearity range was $10-100 \mu \mathrm{g} / \mathrm{mL}$ for losartan, $10-90 \mu \mathrm{g} / \mathrm{mL}$ for hydrochlorothiazide, and 10$150 \mu \mathrm{g} / \mathrm{mL}$ for acetylsalicylic acid. The correlation coefficients were in the range from 0.9987 to 0.9993. The retention times of examined substances were $1.98 \mathrm{~min}$ for hydrochlorothiazide, $3.28 \mathrm{~min}$ for losartan and 8.13 for atorvastatin. The determination results of the individual components in the powdered mixture did not statistically differ from the declared content (RSD 99.08-99.60\%).

Taking into account the way of conducting the analysis, high scientific value has the work in which, besides determination of certain substances in drug formulations, the authors present the possibility of determination of selected active substances or their metabolites in biological material. This type of paper was published in J. Liq. Chromatogr. Related Technol., where a quantitative analysis of the active ingredients present in Star Pill (Cipla Ltd.) with the possibility of their determination in spiked human plasma was presented (25). Both during the analysis of pharmaceutical preparation and biological material, RP-HPLC with KYATECH HiQ Sil C18 HS column $(250 \mathrm{~mm} \times 4.6 \mathrm{~mm})$ and a mobile phase at a flow rate of $1 \mathrm{~mL} / \mathrm{min}$ composed of acetonitrile : $0.02 \mathrm{M}$ potassium dihydrogen phosphate buffer $(\mathrm{pH}$ = 3.4) $(70: 30 \%, \mathrm{v} / \mathrm{v})$ were applied. UV detection was performed at a wavelength of $236 \mathrm{~nm}$.
Hydrochlorothiazide was used as an internal standard. Linearity ranges were different depending on the analyzed material. For the analysis of tablets, the following linearity ranges were used: $20-120 \mu \mathrm{g} / \mathrm{mL}$ for atenolol and losartan, $30-180 \mu \mathrm{g} / \mathrm{mL}$ for acetylsalicylic acid and $4-24 \mu \mathrm{g} / \mathrm{mL}$ for atorvastatin. When spiked human serum was analyzed, the linearity ranges were relatively lower and matched their possible content in biological material. They were respectively $50-300 \mathrm{ng} / \mathrm{mL}$ for atenolol and losartan, 100-600 and 25-150 ng/mL for acetylsalicylic acid and atorvastatin. The retention times of the substances determined were comparable and in both cases ranged from 2-6 min. Mathematically determined limits of detection and limits of quantitation were different because of different linearity ranges. LOD and LOQ of the assay in pharmaceutical preparation were in the range of 0.012-0.032 $\mu \mathrm{g} / \mathrm{mL}$ and $0.029-0.105 \mu \mathrm{g} / \mathrm{mL}$, while the LOQ determined in biological material was in the range from 25 to $100 \mathrm{ng} / \mathrm{mL}$, depending on the determined substance.

The issue of quality control of multi-component pharmaceutical products such as polypills is not only aimed at the possibility of simultaneous determination of individual components, but should also include issues of possible mutual interactions on processes such as absorption or degradation. This subject was taken in the Kumar's publications, which dealt with the possibility of separating and identifying the degradation products in multicomponent preparations used in the form of polypills and described the attempts to determine the degradation mechanism of atenolol, acetylsalicylic acid and lisinopril $(26,27)$. In the study of stability and interactions of the individual components on the degradation process, the authors tested the mixture of hydrochlorothiazide (alternatively atenolol), lisinopril, acetylsalicylic acid and simvastatin (interchangeably atorvastatin or pravastatin). The degradation process was carried out in a climatic chamber for 90 days at $40 \pm 1^{\circ} \mathrm{C}$ at humidity of $75 \pm 3 \%$. After this time, the samples were dissolved in methanol and analyzed using the Supelco C-8 column $(250 \mathrm{~mm} \times 4.6 \mathrm{~mm}$, particle size $5 \mu \mathrm{m})$, oven temperature at $60^{\circ} \mathrm{C}$. The mobile phase at a flow rate of $1 \mathrm{~mL} / \mathrm{min}$ was a mixture of acetonitrile: phosphate buffer $(\mathrm{pH}=2.3)$. Gradient of the mobile phase was adjusted to the currently analyzed mixture. The linearity range of the investigated substances was wide and ranged from $25-250 \mu \mathrm{g} / \mathrm{mL}$, and the determination coefficients in all cases were 0.999. The retention times of the ingredients were about $8 \mathrm{~min}$. for atenolol, $13 \mathrm{~min}$. for hydrochloroth- 
iazide, $20 \mathrm{~min}$ for lisinopril, $32 \mathrm{~min}$ for acetylsalicylic acid, $54 \mathrm{~min}$ for pravastatin, $65 \mathrm{~min}$ for atorvastatin and 72 min for simvastatin. By conducting the degradation process and then analyzing the resulting reaction mixture by LC-MS, the authors observed some regularities. The most stable mixtures were those where hydrochlorothiazide was present instead of atenolol. In the case of hydrochlorothiazide/lisinopril/acetylsalicylic acid/simvastatin mixtures, practically no degradation or interaction effects were observed. In the mixture of similar composition in which simvastatin was replaced with atorvastatin, only one degradation product was observed, and in the case where the statin was pravastatin there were six degradation products. In this case, the authors suggested the possibility of catalytic action of pravastatin on the degradation processes of other substances. Significant degradation and interaction of the substances were observed in the mixtures with atenolol. When hydrochlorothiazide was replaced with atenolol in the mixture, there was a sharp increase in the number of peaks resulting from the degradation products or from the interactions of the individual components. In the case of statins, simvastatin or atorvastatin, additional peaks deriving from ingredients other than those originally present in the mixture were twelve, in the case of pravastatin thirteen. This suggests a very high effect of atenolol on the stability of other substances that may be present in one formulation in the form of a polypill. Continuing their work, the authors attempted to determine the degradation pathways and the resulting degradation or interaction products in a mixture containing lisinopril, atenolol and acetylsalicylic acid. For this purpose, the LC-MS/TOF method was used using similar degradation parameters as described previously. As a result of the analysis five degradation products of atenolol and lisinopril were detected. In the case of atenolol, three of them were identified ( $\mathrm{N}$-acetyl atenolol, O-acetyl atenolol and N,O-diacetyl atenolol) as degradation products while the other two were found to be interaction products of $\mathrm{N}$ acetyl atenolol with salicylic acid and atenolol impurity described in the European Pharmacopoeia (Fig. 1).

Lisinopril under the described conditions degraded to N'-acetyl lisinopril, N,N'-diacetyl lisinopril, and two products of cyclization of diketopiperazine and $\mathrm{N}$-acetyl diketopiperazine lisinopril (Fig. 2).

A manuscript describing the analysis of a mixture of amlodipine, valsartan and hydrochlorothiazide was published in 2017 (28). In the article the authors described the method of separation of the mixture and attempted to investigate the stability of the tested substances under different conditions. Zorbax SB-C8 column was used $(4.6 \times 250 \mathrm{~mm}$, $5 \mu \mathrm{m}$ particle size) for the analysis. A number of stationary phase modifications were studied and the<smiles>CC(=O)OCC(CNC(C)C)OCC(OC(C)=O)N(CC(C)C)C(C)C</smiles>

Figure 1. Products of degradation and interaction of atenolol 


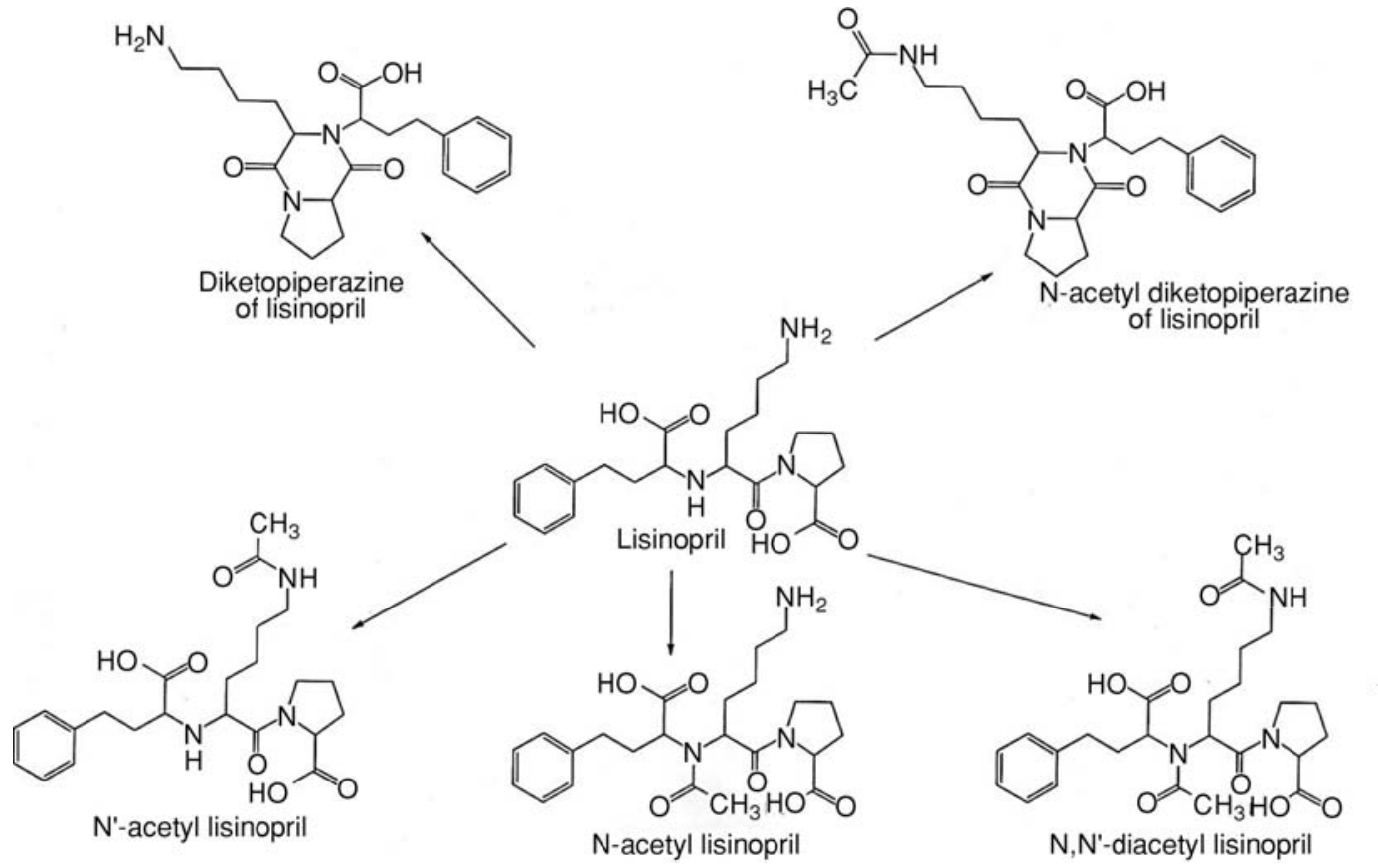

Figure 2. Products of degradation and cyclization of lisinopril

best separation was obtained using a mixture of $0.025 \mathrm{M}$ phosphoric acid: acetonitrile using a linear concentration gradient at a flow rate of $1 \mathrm{~mL} / \mathrm{min}$. Detection was performed at $238 \mathrm{~nm}$ and $225 \mathrm{~nm}$. The linearity range of the described procedure was $5-200 \mu \mathrm{g} / \mathrm{mL}$ for amlodipine and valsartan and 10$200 \mu \mathrm{g} / \mathrm{mL}$ for hydrochlorothiazide. The analysis time did not exceed $10 \mathrm{~min}$ and the retention times were $4.89,6.42$ and $8.29 \mathrm{~min}$ for hydrochlorothiazide, amlodipine and valsartan, respectively. The stability studies were performed in different media and under different conditions. Degradation in acidic and alkaline environments was carried out using $0.1 \mathrm{~mol} / \mathrm{L} \mathrm{HCl}$ or $\mathrm{NaOH}$ solutions at $90^{\circ} \mathrm{C}$ for $1 \mathrm{~h}$. In the case of amlodipine, the degradation time was reduced to $10 \mathrm{~min}$ and the temperature to $60^{\circ} \mathrm{C}$ for basic hydrolysis. Oxidative degradation was carried out in $5 \% \mathrm{H}_{2} \mathrm{O}_{2}$ solution at $80^{\circ} \mathrm{C}$ for $60 \mathrm{~min}$, and in the case of amlodipine the time was extended to $120 \mathrm{~min}$. The photodegradation process was carried out in solid phase by irradiation the powdered substances in UV at a wavelength of $254 \mathrm{~nm}$. for $60 \mathrm{~h}$. Similarly, the substances in solid phase were subjected to the temperature of $90^{\circ} \mathrm{C}$ for $18 \mathrm{~h}$ to determine the effect of high temperature on the stability of the tested substances. Then the solid samples were dissolved, analyzed and chromatographic analysis showed that the lowest stability of the test- ed substances was found in the acidic medium. Under these conditions, amlodipine showed degradation in about $30 \%$, and five degradation products with retention times of $3.18,3.40,4.03,6.06$, and $8.87 \mathrm{~min}$. were detected. In case of valsartan, 2 degradation products with retention times of 3.34 and 9.17 min were present and the substance was degraded in about 50\%. Hydrochlorothiazide proved to be the least stable, its degradation rate was high and reached $75 \%$. In the chromatogram one additional peak with a retention time of $4.53 \mathrm{~min}$. was observed. The degradation process in alkaline medium was the greatest for amlodipine (35\%) and hydrochlorothiazide $(30 \%)$ but for valsartan the degradation rate reached $13 \%$. Amlodipine was found to have two additional peaks of degradation products (5.08 $\mathrm{min}, 6.04 \mathrm{~min}$ ) and hydrochlorothiazide had one additional peak (4.53 min). No additional peaks of degradation products were found for valsartan. The highest sensitivity to oxidation was observed in the case of valsartan (degradation rate about $40 \%$ ), lower in the case of hydrochlorothiazide (30\%). The most stable substance under these conditions was amlodipine with degradation rate about $25 \%$. Analysis of chromatograms registered for amlodipine and hydrochlorothiazide revealed the presence of one additional peak deriving from the degradation product at a retention time of $6.02 \mathrm{~min}$. 


\begin{tabular}{|c|c|c|c|c|c|c|c|c|c|c|}
\hline 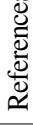 & 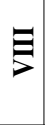 & $\stackrel{\theta}{\sigma}$ & $\Xi$ & $\stackrel{\infty}{=}$ & $\stackrel{Ð}{\triangleq}$ & હ्d & $\widehat{\widehat{d}}$ & $\widehat{\mathbb{d}}$ & $\widehat{\overparen{d}}$ & 经 \\
\hline ه్ & $\xi$ & $\begin{array}{l}\Xi \\
\vdots \\
a \\
\vdots \\
3\end{array}$ & $\begin{array}{l}\text { E } \\
\text { ते } \\
\text { त } \\
3\end{array}$ & 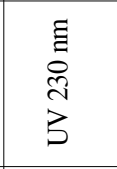 & 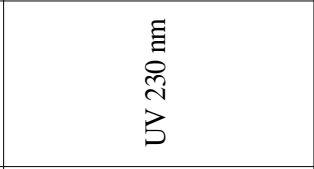 & 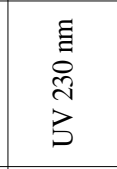 & 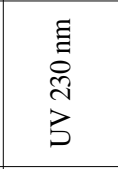 & 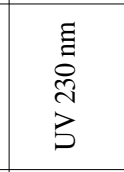 & 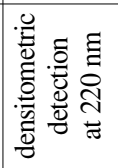 & 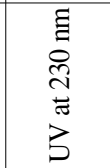 \\
\hline 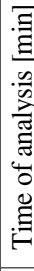 & 5 & $\simeq$ & 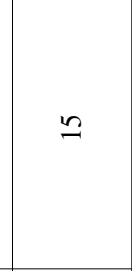 & 요 & ஓ & $\simeq$ & $\simeq$ & శి & $\begin{array}{l}\text { o } \\
0 \\
0 \\
0 \\
0\end{array}$ & ㅇ \\
\hline 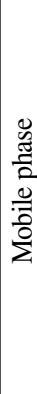 & $>$ & 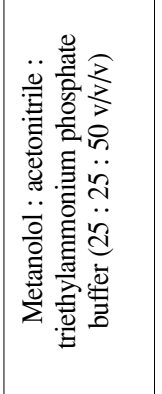 & 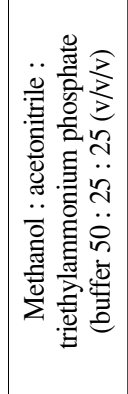 & 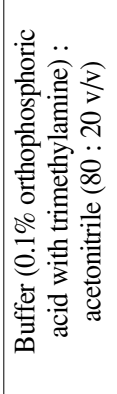 & 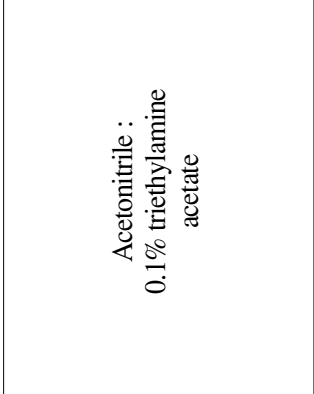 & 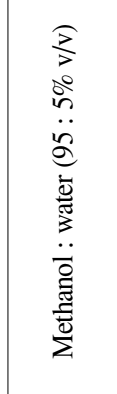 & 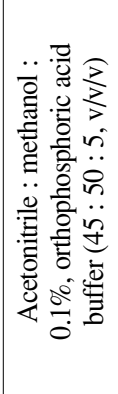 & 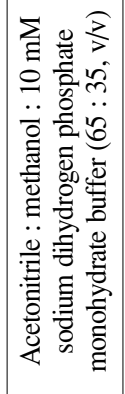 & 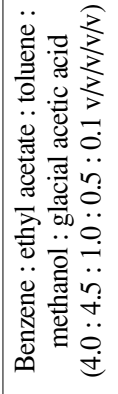 & 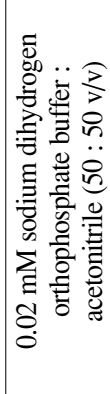 \\
\hline 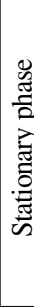 & $\geq$ & 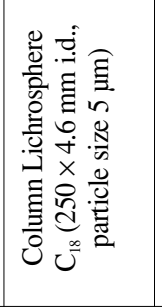 & 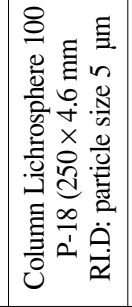 & 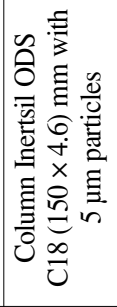 & 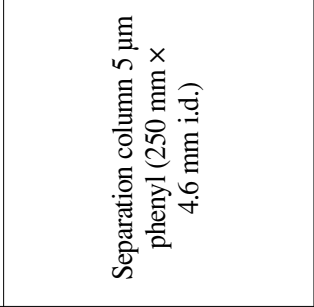 & 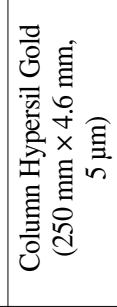 & 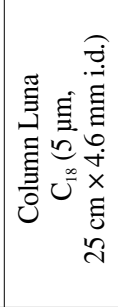 & 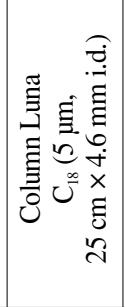 & 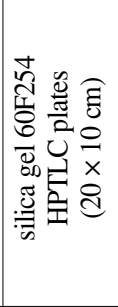 & 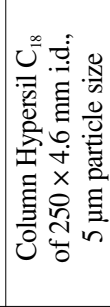 \\
\hline 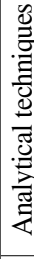 & $\Xi$ & 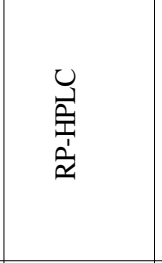 & 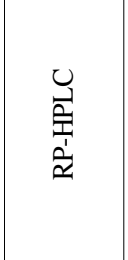 & ב્ય & $\stackrel{\lrcorner}{U}$ & 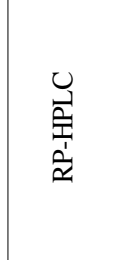 & $\begin{array}{l}0 \\
\stackrel{1}{\simeq} \\
\stackrel{2}{2}\end{array}$ & 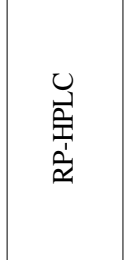 & 岂 & 岂 \\
\hline 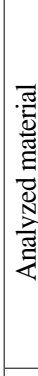 & $=$ & 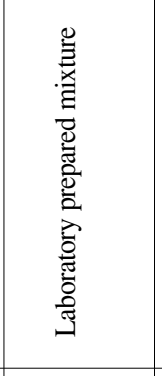 & 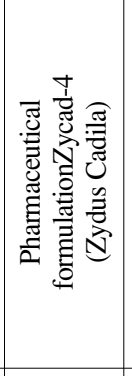 & 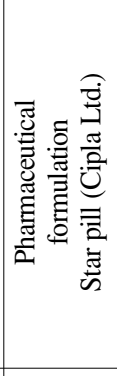 & 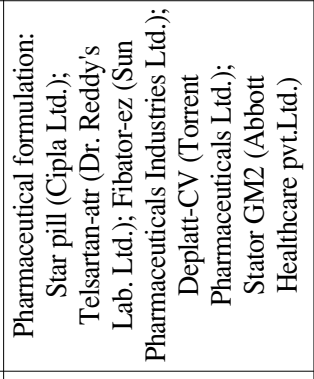 & 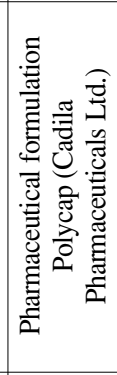 & 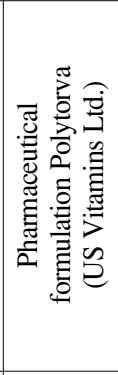 & 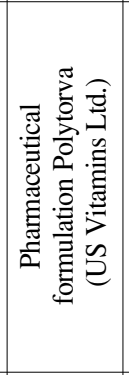 & 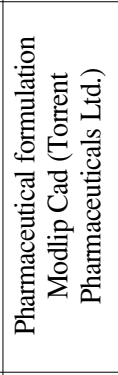 & 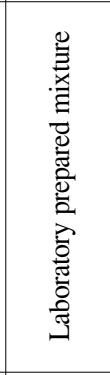 \\
\hline 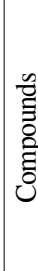 & - & 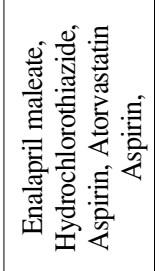 & 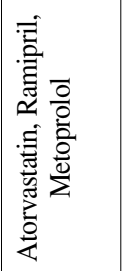 & 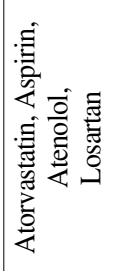 & 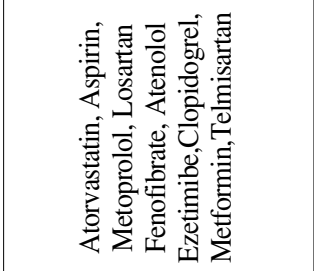 & 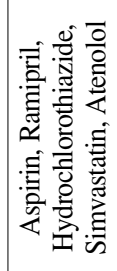 & 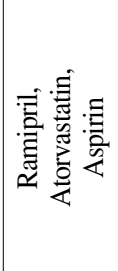 & 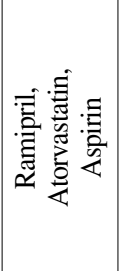 & 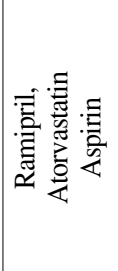 & 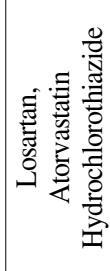 \\
\hline
\end{tabular}




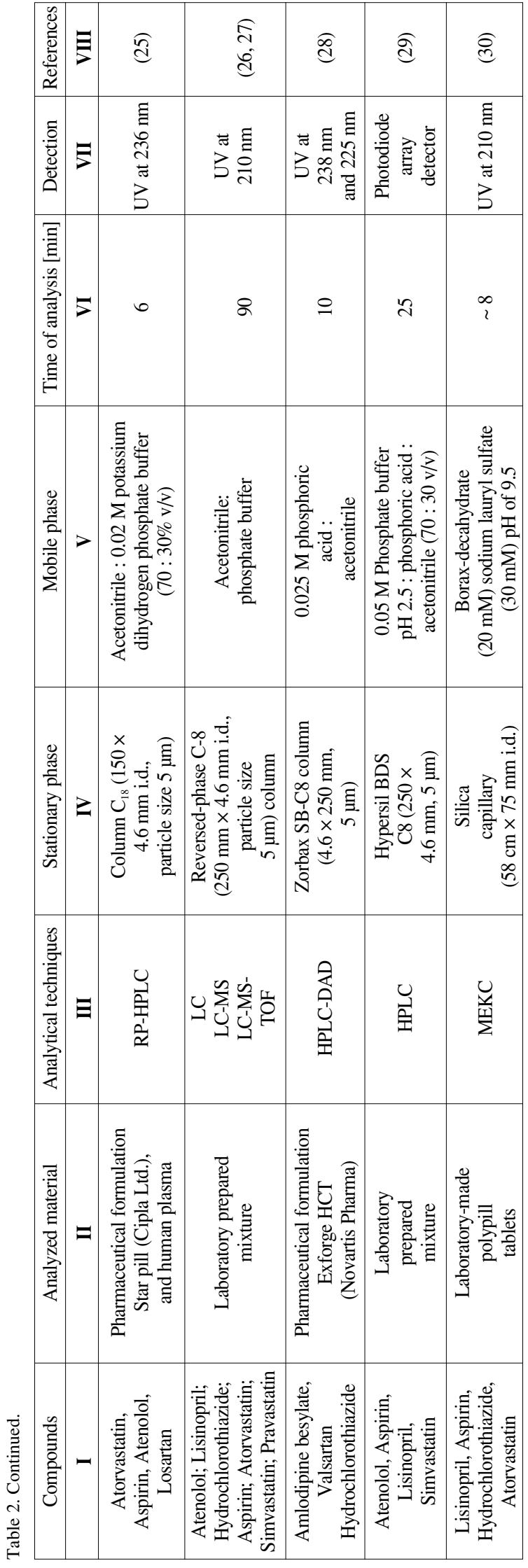

for amlodipine and $4.53 \mathrm{~min}$ for hydrochlorothiazide. Valsartan showed the greatest number of degradation products with retention times of 7.49 , $7.65,7.85$ and $8.04 \mathrm{~min}$. The highest stability of the tested substances was observed in the case of photodegradation and thermo-degradation processes. The most susceptible to photodegradation was hydrochlorothiazide (about 13\%) showing three additional peaks (4.53 $\mathrm{min}, 6.69 \mathrm{~min}, 8.85 \mathrm{~min}$ ). Valsartan, with a degradation rate of about $6 \%$ had three additional peaks at retention times $7.88 \mathrm{~min}$, $9.22 \mathrm{~min}, 9.57 \mathrm{~min}$. Amlodipine did not undergo photodegradation under the described conditions. The highest stability of the tested substances was observed in the case of thermo-degradation, only valsartan was degraded in $5 \%$ and one additional peak appeared at $4.38 \mathrm{~min}$.

Another publication describing the stability studies of active substances that may be in the form of FDC is paper published in the Indian Journal of Pharmaceutical Sciences (29). The authors proposed chromatographic conditions for the separation of a mixture containing atenolol, acetylsalicylic acid, lisinopril and simvastatin, which was subjected to stress tests during the experiment. The mobile phase was a mixture of $0.05 \mathrm{M}$ phosphate buffer $\mathrm{pH}=2.5$ adjusted with dilute phosphoric acid and acetonitrile, and gradient elution was applied. The separation was conducted on a Hypersil BDS C8 column during $25 \mathrm{~min}$. The separation proved to be satisfactory, and characterized by well separated peaks with retention times of 3.97 min for atenolol, $5.82 \mathrm{~min}$ for lisinopril, $9.49 \mathrm{~min}$ for acetylsalicylic acid and 18.36 min for simvastatin. The tested linearity range was wide for all substances and was 12.5 to $75 \mu \mathrm{g} / \mathrm{mL}$ for atenolol, 2.5 to $15 \mu \mathrm{g} / \mathrm{mL}$ for lisinopril, 18.75 to $112.5 \mu \mathrm{g} / \mathrm{mL}$ for acetylsalicylic acid and 5 to $30 \mu \mathrm{g} / \mathrm{mL}$ for simvastatin. The linearity ranges included average daily doses of particular substances commonly used in therapy. In all cases, the correlation coefficient was high $(r>0.999)$. The degradation process of the tested substances was carried out under different conditions: heat $\left(60^{\circ} \mathrm{C}\right)-10$ days, acid $(5.0$ $\mathrm{mol} / \mathrm{L} \mathrm{HCl}$ at $\left.27^{\circ} \mathrm{C}\right)-40 \mathrm{~h}$, base $(5.0 \mathrm{~mol} / \mathrm{L} \mathrm{NaOH}$ at $\left.27^{\circ} \mathrm{C}\right)-30 \mathrm{~h}$ and oxidation $\left(2 \% \mathrm{H}_{2} \mathrm{O}_{2}\right.$ at $\left.27^{\circ} \mathrm{C}\right)-$ $2 \mathrm{~h}$. The chromatograms registered after the degradation process showed the presence of additional peaks; in thermal degradation there were 7 peaks and in other cases 6 . Comparing the retention times presented by the authors, it can be seen that the formation of some products is not strictly determined by the application of certain degradation conditions for active substances. 
Micellar electrokinetic capillary chromatographic method has been successfully used for the quantitative analysis of laboratory-made polypills containing lisinopril, hydrochlorothiazide, acetylsalicylic acid and atorvastatin as active substances (30). The separation was run using silica capillary (58 cm, $75 \mathrm{~mm} \mathrm{ID)} \mathrm{and} \mathrm{a} \mathrm{background} \mathrm{electrolyte}$ solution consisting of borax buffer $(20 \mathrm{mM}, \mathrm{pH}=$ 9.5) containing $30 \mathrm{mM}$ sodium lauryl sulphate and paracetamol as an internal standard, voltage up to 25 $\mathrm{kV}$. The capillary was conditioned prior to injection for a suitable time using $0.1 \mathrm{M}$ sodium hydroxide, water and running buffer. Under these conditions, the authors checked the linearity range and for all substances it was in the range of $0.1-200 \mu \mathrm{g} / \mathrm{mL}$. The determined correlation coefficient was high ( $\mathrm{r}>$ 0.999 ) and limits of detection and quantitation were in the following ranges: LOD $0.33-3.1 \mu \mathrm{g} / \mathrm{mL}$, and LOQ 1.1-10.32 $\mu \mathrm{g} / \mathrm{mL}$ depending on the substance. The retention times presented in the cited work were: $\sim 4 \mathrm{~min}$ for paracetamol (IS), $4.10 \mathrm{~min}$ for lisinopril, $4.25 \mathrm{~min}$. for hydrochlorothiazide, 4.50 min for acetylsalicylic acid, $5.25 \mathrm{~min}$ for salicylic acid as possible impurity of acetylsalicylic acid and $\sim 8.15 \mathrm{~min}$ for atorvastatin. The statistical parameters of the developed method proved its high accuracy and precision. The composition of preparations, the analytical techniques used and their basic parameters are summarized in Table 2.

\section{CONCLUSIONS}

In the presented paper, the authors summarize the analytical methods described in the literature with particular reference to their use in fixed-dosecombination (FDC) product analysis, polypills, used in the treatment of hypertensive disease. Some of the preparations described in the review have undergone clinical trials, and some clinical studies are still being conducted. Due to the increasing number of preparations that can be classified as FDC and the mostly favorable opinions of patients and physicians and representatives of the pharmaceutical industry who have come in contact with such targeted therapies, gathering and describing analytical methods that can be used in quantitative analysis (both in quality control and in stability studies of components) seemed to be important.

\section{Acknowledgement}

The authors gratefully acknowledge the financial support of the grant of the Polish Ministry of Science and Higher Education, K/ZDS/005587.

\section{REFERENCES}

1. Cardiovascular diseases (CVDs), World Health Statistics, Available at http://www.who.int/ factsheets/fs317/index.html. 2015. Accessed 10 Oct 2015.

2. Dalton A.R.H., Sojak M., Samarasundera E., Millett C., Majeed A.: Eur. J. Prev. Cardiol. 20, 142 (2011).

3. Yusuf S., Hawken S., Ôunpuu S., Dans T., Avezum A. et al.: Lancet 364, 937 (2004).

4. Wald N.J., Law M.P.: BMJ. 326, 1427 (2003).

5. Yusuf S., Pais P., Afzal R., Xavier D., Teo K. et al.: Lancet 373, 1341 (2009).

6. Yusuf S., Pais P., Sigamani A., Xavier D., Afzal R. et al.: Circ. Cardiovasc. Qual. Outcomes 5, 463 (2012).

7. Rodgers A., Patel A., Berwanger O., Bots M., Grimm R. et al.: PLoS One 6, e19857 (2011).

8. Malekzadeh F., Marshall T., Pourshams A., Gharravi M., Aslani A. et al.: Int. J. Clin. Pract. 64, 1220 (2010).

9. Wald D.S., Morris J.K., Wald N.J.: PLoS One 7, e41297 (2012).

10. Thom S., Field J., Poulter N., Patel A., Prabhakaran D. et al.: Eur. J. Prev. Cardiol. 21, 252 (2014)

11. Thom S., Poulter N., Field J., Patel A., Prabhakaran D. et al.: J. Am. Med. Assoc. 310, 18 (2013).

12. Soliman E.Z., Mendis S., Dissanayake W.P., Somasundaram N.P., Gunaratne P.S. et al.: Trials 12, 1 (2011).

13. Selak V., Elley C.R., Crengle S., Harwood M., Doughty R. et al.: Contemp. Clin. Trials 32, 909 (2011).

14. Lonn E., Bosch J., Pogue J., Avezum A., Chazova I. et al.: Can. J. Cardiol. 32, 311 (2016).

15. www.secure-h2020.eu, access date February 20, 2017.

16. Pawar A.K.M., Nageswara Rao A.B.N., Sreekanth K., Palavan C., Gowri Sankar D.: J. Pharm. Res. 5, 26 (2012).

17. Pawar A.K.M., Nageswara Rao A.B.N., Gowri Sankar D.: Pharm. Lett. 3, 58 (2011).

18. Shetty S.K., Surendranath K.V., Radhakrishnanand P., Borkar R.M., Devrukhakar P.S. et al.: AJAC 2, 59 (2010).

19. Talluri M.V.N.K., Kalyankar A., Ragampeta S.: J. Pharm. Anal. 2, 285 (2012).

20. Yadav S.S., Rao J.R.: Int. J. Pharm. Pharm. Sci. 6, 443 (2014). 
21. Panchal H.J., Suhagia B.N., Patel N.J., Rathod I.S., Patel B.H.: Chromatographia 69, 91 (2009).

22. Sharma R., Khanna S., Mishra G.P.: E-J. Chem. 9, 2177 (2012).

23. Sharma A.K., Shah B., Patel B.: Der Pharma. Chem. 2, 10 (2010).

24. Ibrahim M.M., Hegazy M.A., El- Aziz El-Bayoumi A., El-Ghani M.A.A.: J. Chem. Pharm. Res. 4, 4737 (2012).

25. Bhatia N.M., Gurav S.B., Jadhav S.D., Bhatia M.S.: J. Liq. Chromatogr. Related Technol. 35, 428 (2012).
26. Kumar V., Shah R.P., Singh S.: J. Pharm. Biomed. Anal. 47, 508 (2008).

27. Kumar V., Malik S., Singh S.: J. Pharm. Biomed. Anal. 48, 619 (2008).

28. Shaalan R.A., Belal T.S., El Yazbi F.A., Elonsy S.M.: Arab. J. Chem. 10, 1381 (2017).

29. Mallikarjuna Rao N., Gowrisankar D.: Indian J. Pharm. Sci. 78, 217 (2016).

30. Alzoman N.Z., Alshehri M.M., Sultan M.A., Maher H.M., Olah I.V., Darwish I.A.: Anal. Methods 5, 1238 (2013).

Received: 28.11.2017 